\title{
Community Perceptions Regarding Drug and Substance Abuse and Intervention Programmes in Kenya: Implications for Promoting Well-Being for All
}

\author{
Ruth N. Simiyu \\ Department of Peace and Conflict Studies \\ School of Disaster Management and Humanitarian Assistance \\ Masinde Muliro University of Science and Technology \\ Kenya
}

\begin{abstract}
The overall objective of this study was to evaluate preparedness of communities for response to drug and substance abuse (DSA) in Kenya. One of the specific objectives examined the perceptions of the communities regarding drugs, DSA and intervention. The study site was Bungoma County, Western Kenya. The parameters of inquiry were perceptions of the community on: effects of drugs, reasons for DSA, sources of drugs, treatment and rehabilitation, vulnerabilities and capacities in the community. The study found diverse opinions in the community on whether and how various drugs are harmful or beneficial to the users. Perceived reasons for DSA were influence from peers and family 246(61.6\%); idleness 208(52.1\%) and stress/frustration 170(42.6\%). Other reasons were medical, where some drugs were perceived to have medicinal value. Household respondents felt that police $235(58.9 \%)$ and the chiefs $216(54.1 \%)$ were the most suitable for controlling to DSA followed by teachers (42\%) and parents 40.6\%. Majority of household heads, 257(64.4\%) were not confident about handling DSA problems in their households and require training and awareness in all aspects of DSA. Over 50\% admitted that they required education and training in all aspects of DSA including: types of drugs, effects of drugs; how to recognize DSA in the family; how to deal with traffickers; how to cope with drug abuse problems among others. The study recommended that there should be more intensive and frequent dissemination of information from research and surveillance to increase awareness. All stakeholders should undergo appropriate formal and informal training, seminars and in-servicing on DSA. These should help to improve the perceptions towards drugs, DSA and intervention. For the purpose of accountability, there is need to appoint a body in every county in Kenya and charge it with the sole responsibility of coordinating activities of prevention, control, intervention and awareness creation. The appointed body should create mechanisms of building and equipping treatment, counselling and rehabilitation centres. It should also work out modalities of ensuring addicts and affected families are reached out to and rehabilitated.
\end{abstract}

Keywords: Community Preparedness, Perceptions, Response, Drug and Substance Abuse, rehabilitation, Wellbeing, Sustainable Development Goals, Kenya

\section{Introduction}

Despite most governments world over making an effort, in collaboration with the international community to eradicate harmful use of drugs, research by UNCPD (2006) shows that effective response can be achieved only when local communities take ownership of their drug problems. This is because the communities are aware of the context in which the drugs are supplied, consumed and the impact. In relation to the foregoing theory, and from the understanding that a community is not merely an aggregate of individuals but also a set of relations in which individuals are grouped into different categories such as social classes, clans, ethnic groups, age-sets, we can expect these relations to influence DSA among stakeholders. Such cultural relations are strong in Kenya (Ogutu, 1985) and their association with DSA needs to be well investigated.

NACADA Authority, in partnership with the international community has been training communities including professionals, parents and individuals in Kenya for effective response (NACADA, 2010; WHO, 2007). National campaign Against Drug and substance abuse (NACADA), a state agency in Kenya which came into existence through a Gazette Notice number 284 in 2001 is mandated to coordinate activities of individuals and 
organisations in the campaign against drug abuse in Kenya. Some of the activities it focuses on are to initiate public education against DSA; develop strategies aimed at curbing DSA among the youth; sensitize parents on the abuse of drugs and their functions as role models and to initiate rehabilitation programmes for drug dependent persons.

WHO (2006) points out that it is necessary to carry out frequent focused research to identify emerging drugs, any modifications to common ones (such as alcohol) and to be aware of new trends that may pose health risks to the community. The study also recommended that it is necessary to examine the perceptions of the community in a region regarding the drugs and interventions for appropriate strategies to be planned and implemented effectively. These aspects of DSA in Kenya are not well known apart from those of illicit brews (Simiyu, 2011). Furthermore, DSA continues to increase in Kenya, thereby affecting development (GOK, 2009). These are an indication of needs or gaps in the mode and level of preparedness for response to DSA that need to be addressed for the fight against the vice to be successful and to meet the international standards as envisioned in the SDGs for well-for all.

\section{Methodology}

The site of study was Bungoma County in 2012-2013 in three sub-counties, which were selected for study through multi-stage random sampling. These were Bungoma East, Bungoma South and Mt Elgon. The purpose was to evaluate preparedness of the community for response to DSA. Cross-sectional, cross-cultural and evaluation research designs were employed. Homogeneous and heterogeneous groups were selected by nonprobability sampling. Multi-stage random sampling was used to select 399 household heads for questionnaires. The 114 professionals and leaders from education, medical and health, law enforcement, Faith Based Organisations and political sectors were selected purposively and responded to interview schedules, FGDs and community vulnerability assessment (CVA) guides. Observation method was also used to collect data. Data analysis provided frequencies, percentages, rank order and Chi-squares $\left(\chi^{2}\right)$.

\section{Results and Discussion}

This section provides results on the perceived effects of drugs, reasons for DSA, sources of drugs, treatment and rehabilitation and aspects of DSA in which more awareness, training is required in the community.

\subsection{Perceptions on Effects of Drugs to the Community}

Perceived risk per drug (whether harmful, not harmful, beneficial or not sure) when used in the community are displayed in Table 1.

Table 1: Perceptions regarding whether selected drugs are Harmful or Beneficial in the community

\begin{tabular}{|c|c|c|c|c|c|}
\hline \multirow[t]{2}{*}{$\begin{array}{l}\text { Type } \\
\text { Drug }\end{array}$} & Harmful & Not Harmful & Beneficial & Not Sure & $\chi^{2}$ \\
\hline & f $\%$ & f $\%$ & $\%$ & f $\%$ & \\
\hline Alcohol & $91(22.8)$ & $83(20.8)$ & $65(16.3)$ & $160(40.1)$ & 0.858 \\
\hline Bhang & $159(39.8)$ & $9(2.3)$ & $7(1.8)$ & $224(56.1)$ & 0.858 \\
\hline Tobacco & $106(26.6)$ & $171(42.9)$ & 79 (19.8) & $43(10.8)$ & $51.430 * *$ \\
\hline Kuber & $12 \quad(3.0)$ & $103(25.8)$ & $56(14.0)$ & $228(57.1)$ & $52.340 * *$ \\
\hline Miraa(khat) & $9 \quad(2.3)$ & $85(21.3)$ & 92 (23.6) & $213(53.4)$ & $37.077 * *$ \\
\hline Caffeine & $7 \quad(1.8)$ & $341(85.5)$ & $49(12.3)$ & $2(0.5)$ & 6.003 \\
\hline Inhalants & 166 (41.6) & $46(11.5)$ & $31(1.8)$ & $157(39.4)$ & $18.691 * *$ \\
\hline Prescription & $67(16.8)$ & $197(49.4)$ & $109(27.3)$ & $26(6.5)$ & $161.85^{* *}$ \\
\hline
\end{tabular}

Source: Field Data (2012)

The differences in perception about the harmfulness of drugs at d.f $=4$ show a highly statistical significance in tobacco $(\chi 2=51.430 ; \mathrm{p}=0.000)$, kuber $(\chi 2=52.340 ; \mathrm{p}=0.000)$, miraa $(\chi 2=37.07 ; \mathrm{p}=0.000)$ inhalants $(\chi 2=18.691 ;$ 
$0.005)$ and prescription drugs $(\chi 2=161.85 ; \mathrm{p}=0.000)$. However, there is no significant difference in perception regarding the harmfulness in abuse of alcohol, bhang and caffeine among household heads. More household heads were of the opinion that alcohol, bhang and inhalants are harmful compared to those who felt that the drugs are not harmful. Most admitted that alcohol and bhang cause health problems, violence and poverty in the home, loss of employment and drop-outs from school among students. However, some others felt that the drugs are beneficial to some extent, claiming that alcohol and tobacco are medicinal.

In the case of bhang, a few respondents, 7(1.8\%) claimed that it was beneficial since those who consume it are more active and energetic for menial work. They further claimed that it is a source of income for the dealers. Over one third 159(39.8\%) however submitted that bhang was harmful and caused mental and addiction problems, which depleted family resources. A small proportion 26(6.5\%) was not sure whether caffeine and prescription drugs were harmful.

These results on perceptions mirror those of a study by NACADA (2007) on the attitudes of respondents toward drugs, which suggested that majority of Kenyans hold positive attitudes towards consumption of licit drugs, particularly cigarettes $(73 \%)$, packaged liquor $(72 \%)$, traditional brew $(69 \%)$, tobacco $(68 \%)$ and miraa $(54 \%)$. In contrast however, illicit drugs such as cocaine and heroin had a low acceptability (4-5\%), illicit brew (34\%) and bhang (12\%). In the cited study (Ibid.), perceptions towards drugs differ in various regions in Kenya. For instance, miraa had the highly accepted in Eastern Province. Acceptability of cigarettes was over $65 \%$ in all the regions except the North Eastern. Bhang, chang'aa (homemade alcoholic spirit), heroin and cocaine had high acceptability in Nairobi and conventional alcohol in Central Province of Kenya.

Similar results were found in a study among high school students on risk perception among adolescents in six South American countries (Argentina, Chile, Bolivia, Ecuador, Peru, and Uruguay) (Bejarano et al., 2011). The study found different perceptions by country, gender of the adolescents and the nature of the drugs (licit or illicit). Respondents with low and unknown (not sure) perception of harm associated with use of any substances were more likely to abuse those substances compared to those who were sure of the risks, with corresponding implications on their well-being.

\subsection{Perceptions Regarding Risk Factors in DSA}

Reasons for DSA as perceived by household respondents are shown in Fig.1. Chi-square test of independence across the districts at d.f. $=12$ shows that there is a significant difference in DSA with respect to medicinal reasons $(\chi 2=7.306 ; \mathrm{p}=0.026)$. The analysis further shows that the difference is significantly high in the districts with regard to idleness $(\chi 2=21.814 ; \mathrm{p}=0.000$, easy availability $(\chi 2=14.375 ; \mathrm{p}=0.001)$ and cultural reasons $(\chi 2=34.448$ $\mathrm{p}=0.000$. However, there is no significant difference between the districts with regard to 'to socialise', 'be active/alert', 'relieve stress/frustration', to satisfy addiction, fun/enjoyment, influence and 'Other' reasons.

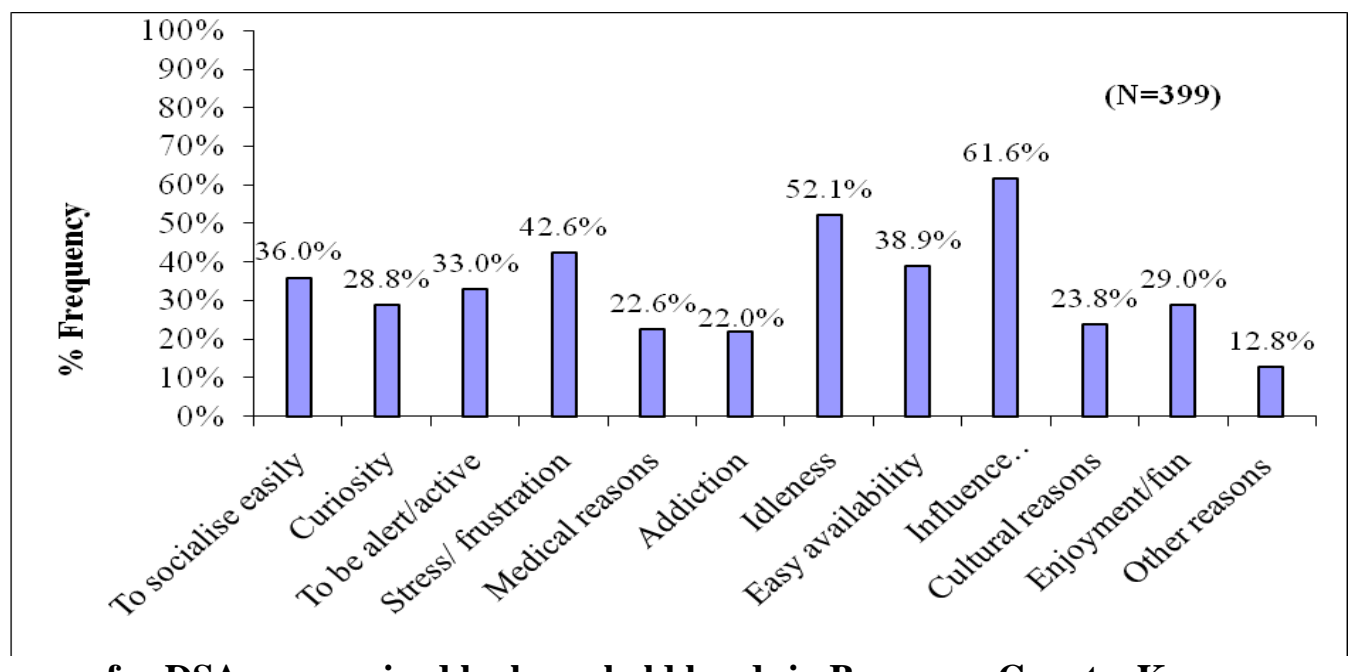

Figure 1: Reasons for DSA as perceived by household heads in Bungoma County, Kenya

(Field Data, 2012) 
A scrutiny of the overall results shows that the main reasons for DSA were influence from peers and family 246(61.6\%); idleness 208(52.1\%) and stress/frustration 170(42.6\%), where alcohol was the main drug used to reduce stress/frustrations due to unemployment, hard life and marital problems. Other reasons were medical such as to cure typhoid; busaa (fermented brew) to treat anaemia, tobacco snuff for nose bleeding and cigarettes to prevent pneumonia among others. 'Other' reasons were to manage doing certain jobs well, for example bhang for menial workers, cigarettes and alcohol for night guards, tobacco snuff and inhalants among the matatu (commuter van) and boda boda (motorcycle transporters).

The results concur with those from FGDs with regard to stress/frustration; to get courage to do certain things such as crime and gay activities, which they said were common among them. The participant abusing the pain killer disclosed that he started using the drug after hospitalisation from an accident but got addicted.

Injecting drug users (IDUs), when asked whether they wished to stop the habit said that they were already addicted and only wanted the researcher to liaise with DASCO officials to help provide free needles and syringes to avoid transmission of HIV and HBV. School boys pointed out in FGDs that the rate of abuse of drugs among students becomes higher during the national examination period. They argued that they required stimulants particularly coffee, alcohol, bhang and miraa to keep awake/alert, purportedly to read for longer hours at night as they prepare for examinations.

Boda boda revealed that they consumed alcohol on their way back home in the evening to help them relax after the day's work. Thus late evening and night time boda boda passengers risk accidents as they are likely to be carried by drunken transporters. The motor cyclists also admitted regular use of tobacco snuff, supposedly to prevent colds, nose bleeding and respiratory problems. From observation, majority of motorcycle transporters did not use the helmet and warm jackets as required by Traffic Act Cap 403 Section 119 (GOK, 2008). Instead, they reported that they use snuff, which they claimed helps to ventilate the chest and prevent colds and pneumonia.

Matatu (commuter vans) touts claimed that since they wake up very early in the morning to begin their daily work in the transport industry, miraa was very useful for keeping them awake during the day. Out of 12 participants in the FGD, those who used kuber (6) claimed to prefer it to other psychoactive drugs for its convenience in use; as it is used by simply keeping it in the mouth without leaving their job to go and use or search for it whenever they needed to be high. More girls (5) than boys (2) abused prescription drugs including pain killers and piriton claiming that they relieve menstrual pains colds and headache; and induce sleep respectively whenever they wanted to rest fully.

Reasons for DSA found in this study concur with those from various studies. Ngesu et al. (2008) in a survey in secondary schools in Kisumu Municipality found the same reasons, among them peer influence, parental drug abuse, curiosity and fun and stress. According to Vlahov (2002), DSA is a form of self medication for PTSD as found among disaster victims of the US bombing in 2001. Other stressful conditions in the community include poverty and associated day to day hardships; marital problems; unemployment; chronic diseases among others. Other studies confirm that the type of occupation can be a reason for DSA as found in Australia among health workers (Kenna \& Lewis, 2008).

\subsection{Perceptions on Sources of Drugs (Further risk factors) in the Community}

Chi-square analysis of responses in Table 2 indicates that there are no significant differences in perceptions on the sources of most drugs $(\mathrm{p}>0.05)$. However, at d.f. $=4$ there was a significant difference $(\mathrm{p}<0.05)$ with regard to the bar as a source of bhang $(\chi 2=10.361 ; \mathrm{p}=0.035)$; relatives for tobacco $\left(\chi^{2}=7.062 ; \mathrm{p}=0.029\right)$; work place for tobacco $(\chi 2=11.907 ; \mathrm{p}=0.003)$ and a highly significant difference in the street for miraa $(\chi 2=14.483 ; \mathrm{p}=0.001)$. Major sources of some of the drugs are the households, especially caffeine 306(76.7\%) and alcohol 112(28.0\%); and neighbourhood for alcohol 96(24.0\%) and tobacco 51(12.5\%) which respondents said is sold openly in the market alongside other common goods (Plate 1). 
Table 2: Sources of Drugs as perceived by household heads in Bungoma County, Kenya

\begin{tabular}{lllllllll}
\hline Source & Alcohol & Bhang & Tobacco & $\begin{array}{l}\text { Miraa } \\
\text { (khat) }\end{array}$ & Kuber & Caffeine & Inhalants & $\begin{array}{l}\text { Prescrip- } \\
\text { tion }\end{array}$ \\
\hline & f \% & f $\%$ & f $\%$ & f \% & f \% & f \% & f \% & f \% \\
\hline Household & 112 & $2(0.5)$ & $17(4.3)$ & $1(0.3)$ & & 306 & $5(1.3)$ & $98(24.6$ \\
& $(28.0)$ & & & & $0(0.0)$ & $(76.7)$ & & \\
Neighbour- & $96(24.0$ & $26(6.5$ & $51(12.5$ & $3(0.8)$ & $8(2.0)$ & $11(2.8)$ & $2(0.5)$ & $9(2.3)$ \\
Supermarket & $12(3.0)$ & $0(0.0)$ & $6(1.5)$ & $0(0.0)$ & $0(0.0)$ & $0(0.0)$ & $17(4.3)$ & $12(3.0)$ \\
Friends & $13(34.8$ & $17(4.3$ & $28(7.0)$ & $4(1.0)$ & $11(2.8$ & $9(3.3)$ & $3(0.8)$ & $8(2.0)$ \\
Relatives & $47(11.8$ & $2(0.5)$ & $3(0.8)^{*}$ & $1(0.3)$ & $0(0.0)$ & $5(1.3)$ & $0(0.0)$ & $2(0.5)$ \\
School & $51(12.8$ & $16(4.0$ & $16(4.0)$ & $3(0.8)$ & $9(2.3)$ & $6(1.5)$ & $8(2.0)$ & $5(1.3)$ \\
Work place & $36(9.8)$ & $11(2.8$ & $37(9.3 *$ & $9(2.3)$ & $13(3.3$ & $4(1.0)$ & $21(5.3$ & $2(0.5)$ \\
Club/chama & $8(2.0)$ & $3(0.8)$ & $1(0.3)$ & $0(0.0)$ & $0(0.0)$ & $5(1.3)$ & $0(0.0)$ & $0(0.0)$ \\
Bars & $92(23.0$ & $0(0.0 *$ & $7(1.8)$ & $0(0.0)$ & $3(0.8)$ & $0(0.0)$ & $0(0.0)$ & $0(0.0)$ \\
Streets/kiosk & $4(1.0)$ & $0(0.0)$ & $22(5.5)$ & $12(3)$. & $8(2.0)$ & $0(0.0)$ & $8(2.0)$ & $9(2.3)$ \\
& & & & $* *$ & & & & \\
Other & $1(0.3)$ & $0(0.0)$ & $0(0.0)$ & $4(1.0)$ & $2(0.5)$ & $0(0.0)$ & $8(2.0)$ & $4(1.0)$ \\
\hline
\end{tabular}

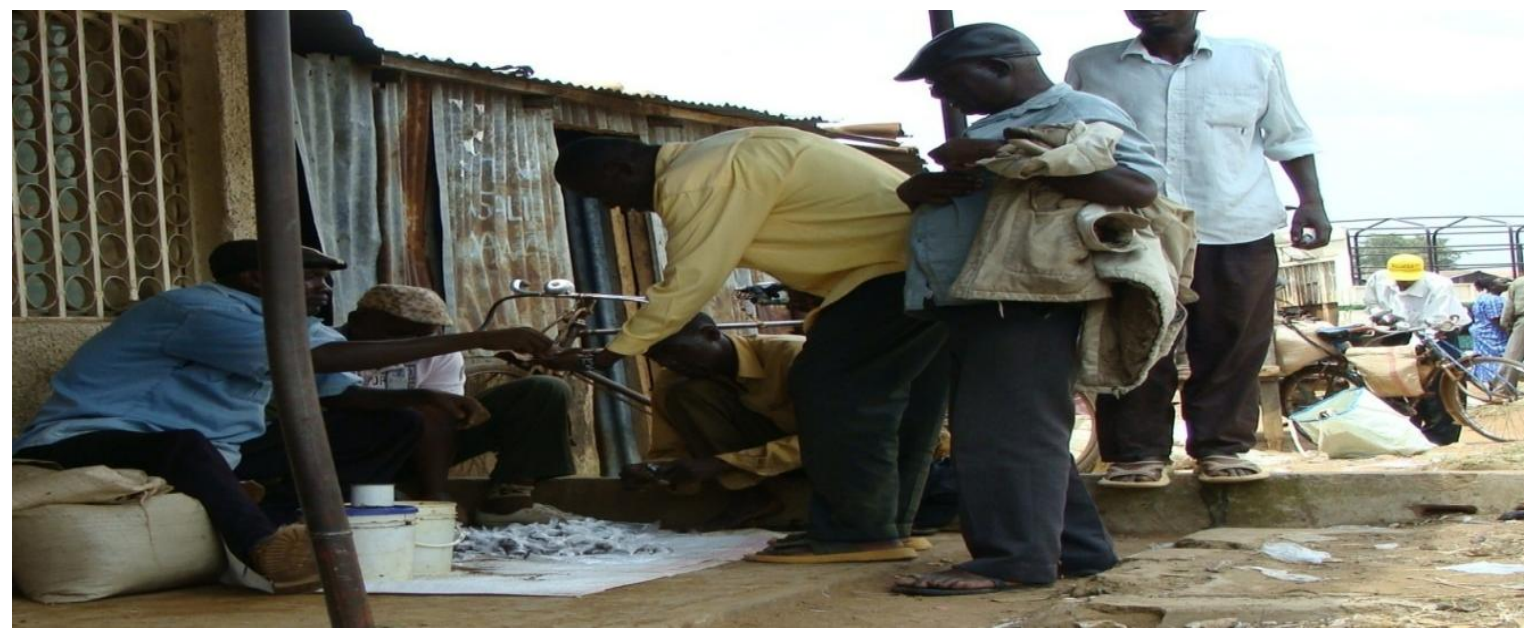

Plate 1: Men Buying Tobacco Snuff (in buckets and mugs) from a Wholesaler in Webuye Open-air Market in Bungoma County, Kenya; Source: Field Data (2012)

The open air market (Plate 1) is a source of drugs such as tobacco snuff and unprocessed tobacco for smoking and chewing. It is also a source of miraa; kuber and chang'aa. The findings on these sources concur with those from FGDs where boys in school revealed that school workers and day scholars in schools with both day and boarding sections are other peddlers. They further disclosed that some teachers connect their students to drug peddlers. Other sources were school laboratories and neighbours who sell them, especially alcohol and bhang across the school fence.

The FGDs further revealed that drivers of transit vehicles from Mombasa to Uganda sell drugs at stop-overs along the highway at Dina Junction in Webuye town, Bukembe Market and Kanduyi stage in Bungoma County, Kenya. Additionally, they revealed that Kenyan students in nighbouring Uganda were other sources of drugs for the youth in school in the county. Pharmacist at Webuye District Hospital revealed that there were incidences of subordinate staff, especially those who easily access hospital wards, such as cleaners stealing prescription drugs for sale. The drugs, including valium, phenobarbitones, pain killers, anti-acids, cough mixtures and antibiotics. They are stolen and sold to clients out of hospital at a lower price than the local chemists.

Similar perceptions about households and neighborhoods being sources of drugs were found in a study in Kieni East Division of Nyeri North District in Kenya in households. The respondents cited rampant brewing along nearby rivers; and bhang being planted in the nearby Mt. Kenya forest and peddled in the area. 


\subsection{Perceptions on the Role of Stakeholders on Prevention and Intervention in DSA}

Fig. 2 presents the overall results on who is perceived as the most suitable stakeholder to handle DSA in the community.

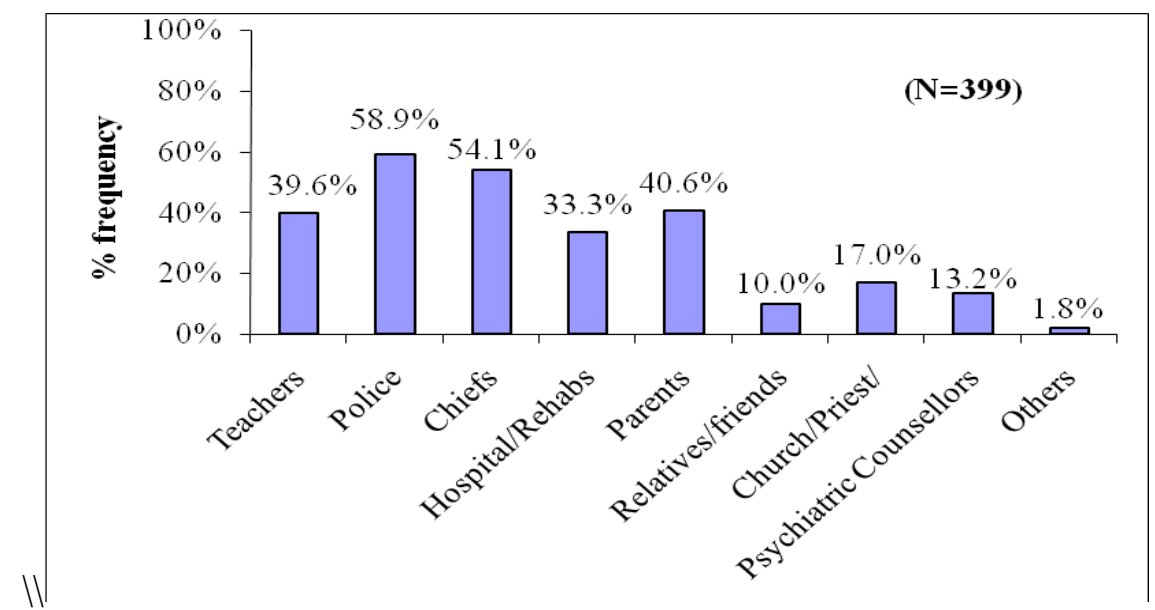

Figure 2: Perceptions regarding who should deal with DSA in the community in Bungoma County, Kenya

Chi-square test of independence at d.f $=8$ show a statistically significant difference in perception across the districts regarding parents $(\chi 2=7.295 ; 0.026)$ and relatives and friends $(\chi 2=7.295 ; 0.038)$. The analysis shows a highly significant differences in perception regarding police $(\chi 2=138.866 ; \mathrm{p}=0.000)$, chiefs $(\chi 2=6.160 ; 0.000)$, public health $(\chi 2=141.313 ; 0.000)$ and psychiatric counsellors $(\chi 2=11.321 ; 0.009)$. However, there were no significant differences in the districts $(\mathrm{p}>0.05)$ in perceptions regarding priests and teachers. Although the household respondents felt that the police 235(58.9\%) and the chiefs 216(54.1\%) were the most suitable, FGDs found that parents should play a major role by making the home environment more conducive and by creating awareness on dangers of DSA in their families. They argued that parents should play this role by providing basic needs for their families, take their children to school and not abuse drugs especially in the presence of children.

These findings pattern those of a study by NACADA (2005) in Nairobi to find out the perceptions of parents concerning who should prevent DSA among school children where it was found that over $42 \%$ felt that teachers should deal with the problem. They expected other stakeholders in the community to have a greater responsibility of responding to DSA than them.

\subsection{Perceptions on whether Respondents Feel Confident about Handling DSA issues in the Community}

Results in Fig. 3 show whether parents feel confident to handle DSA in the community or not.

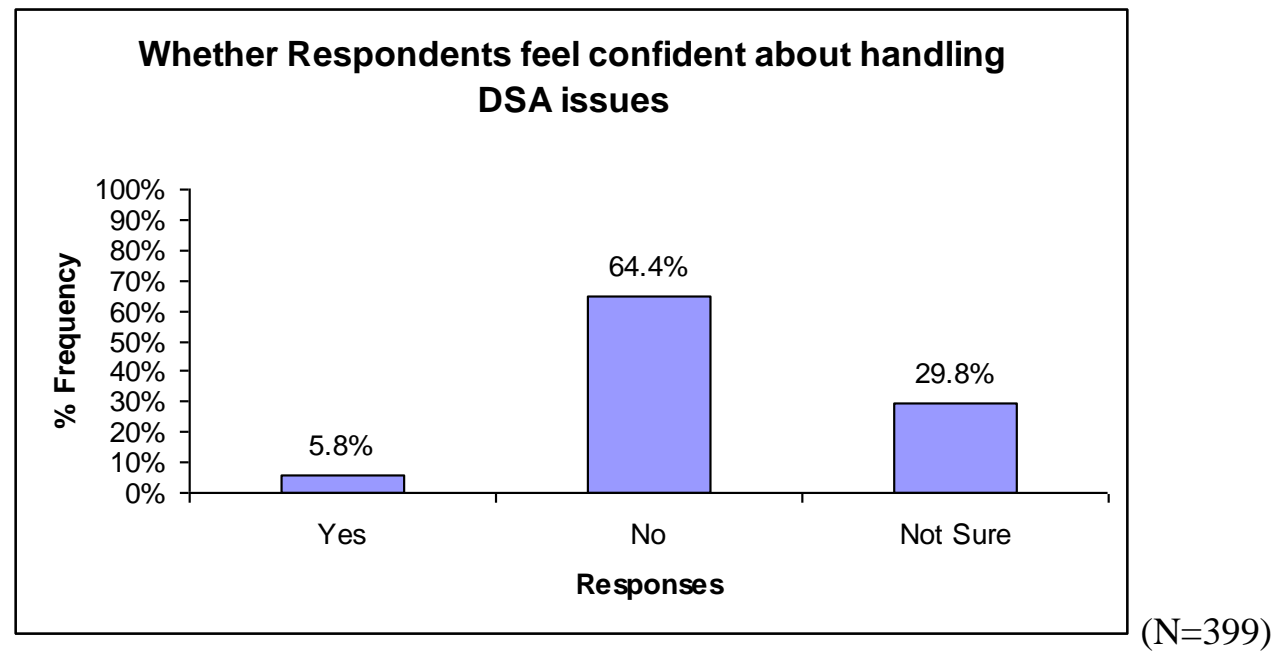

Figure 3: Whether household heads feel confident to handle DSA in their households in Bungoma County, Kenya (Source: Field Data, 2012) 
Chi-square analysis of results from the three districts indicates that there is a statistically significant difference $(p<0.05)$ in confidence with regard to districts $(\chi 2=10.337$; d.f. $=4 ; p=0.035)$. This is because Mt. Elgon had a very small percentage $2(1.5 \%)$ that was confident compared to Bungoma East $8(6.0 \%)$ and Bungoma South 13(9.8\%). Majority of household heads, 257(64.4\%) were not confident about handling DSA problems in their households. Some admitted that in the first place they did not know some of the drugs while others were not sure whether any family members abused drugs and the particular drugs abused.

Household heads, claimed that they lacked guidance and counselling skills while others submitted that they were already using some of the drugs themselves and did not have moral authority to deal with such issues confidently. They further submitted that they were not sure at what stage to take the drug abusers for rehabilitation since they viewed rehabs as very expensive and mainly for people with very serious addiction (mental) problems. Furthermore they doubted the effectiveness of rehabilitation programmes in Kenya. They perceived hospitals in neighbouring Uganda and herbal medicine cheaper and more effective alternatives for treatment and rehabilitation of DSA problems.

The 23(5.8\%) parents who were confident to deal with DSA problems claimed that they did so by being role models to their family members in their behaviour; talking to them on dangers of drugs regularly and by being close enough to monitor the behaviour of their children. However, 119 $29.8 \%)$ were not sure whether they can handle DSA problems or not. Further probing revealed that they did not know some of the drugs apart from the common ones such as alcohol and tobacco. Others admitted that they had not encountered DSA problems in their families, so had no experience while others claimed that their nature of work did not give them time to monitor their family but relied on relatives for solutions to such problems.

The low confidence (5.8\%) expressed by respondents in this study can be explained by lack of training and awareness as found in a study in Baltimore, US which showed that training has a positive effect on selfperception, competence and confidence among those working with DSA clients (Bina et al., 2008). The cited study further confirmed that formal training is a stronger predictor of a feeling of preparedness compared to informal training among stakeholders.

\subsection{Perceptions on Aspects of DSA in which Further Awareness/Training is needed}

When asked the areas they felt most inadequate in drug issues, the responses from household heads were as shown in Table 3.

Table 3: Aspects of DSA in which Household Heads require more Awareness/Training in Bungoma County, Kenya

\begin{tabular}{|l|c|l|}
\hline Aspects of DSA & Household Heads & \\
\hline & (f) \% & $\chi 2$ \\
\hline Types of drugs & $391 \quad(98.0)$ & 2.046 \\
\hline Effects of drugs & $394(98.8)$ & 2.067 \\
\hline $\begin{array}{l}\text { How to recognize drug abuse in the } \\
\text { family }\end{array}$ & $373(93.5$ & 2.765 \\
\hline $\begin{array}{l}\text { How to prevent drug abuse in the } \\
\text { family }\end{array}$ & $388(97.2)$ & 0.748 \\
\hline How to deal with drug traffickers & $124(31.8)$ & $11.094^{*}$ \\
\hline $\begin{array}{l}\text { How to cope with drug abuse } \\
\text { problems }\end{array}$ & $342(85.7)$ & 0.682 \\
\hline $\begin{array}{l}\text { How to reduce/minimise effects on } \\
\text { abusers and families }\end{array}$ & $211(52.9)$ & 3.005 \\
\hline Source Fin
\end{tabular}

Source: Field Data, 2012

Chi square analysis of results in Table 3 shows that the aspect of how to deal with drug traffickers $(\chi 2=11.094$; $\mathrm{p}=0.004)$ was found to have high statistical difference $(\mathrm{p}<0.05)$ compared to the others. 
In this aspect only $127(31.8 \%)$ felt that they required education and training as they felt that it was the work of law enforcers to deal with traffickers. They pointed out that drug trafficking is a complicated, sensitive and risky matter in which they did not wish to get involved. Over 50\% admitted that they required education and training in all aspects of DSA as indicated. Most professionals and leaders in the interview also expressed similar needs for training and awareness. These findings, point to the fact that parents may not always know the types of drugs abused by their children and the effects of the drugs. In the study by NACADA (2010) in Nairobi and its environs to establish the knowledge of parents in DSA issues, it was found that although they knew of common substances abused, prescription drugs and amphetamines were not well known by most of them.

\section{Conclusions and Recommendations}

The study found divergent views on the effects of drugs from respondents, with most of the perceptions posing hindrance to prevention, control and intervention especially of the licit drugs (alcohol, tobacco). The perceptions given in the study were an indicator of socio-economic conditions and lack of awareness and training in DSA issues in the community. Majority of respondents felt that more awareness is required on types and effects of drugs. Additionally, no section of the community felt responsible for handling drug problems but each expected the other stakeholders to play a bigger role. There is need for more intensive and frequent dissemination of information from research and surveillance to increase awareness in the community. All stakeholders should undergo appropriate formal or informal training, seminars and in-servicing on DSA. These should help to improve the perception of the community towards drugs, DSA and intervention. For the purpose of accountability, there is need to appoint a body in every county in Kenya and charge it with the sole responsibility of coordinating activities of prevention, control, intervention and awareness creation. The appointed body should create mechanisms of building and equipping treatment, counselling and rehabilitation centres. It should also work out modalities of ensuring all addicts and affected families are reached out to and rehabilitated for the SGDs to be realised.

\section{References}

Bina, R., Harnek Hall, D.M., Mollette, A., Smith-Osborne, A., Yum, J., Sowbel, L. \& Jani, J. (2008). Education; Sociology and social work. Journal of social work Education, vol. 44 Number 3.

Bejarano, J., Ahumada, G., Sánchez, G., Cadenas, N., de Marco, M., Hynes, M. \& Cumsille, F. (2011). Perception of Risk and Drug Use: An Exploratory Analysis of Explanatory Factors in Six Latin American Countries. The Journal of International Drug, Alcohol and Tobacco Research, Vol. 1, No. 1, 9-17.

GOK (2009). Bungoma District Development Plan (2002-2008). Ministry of Planning and National Development. Nairobi. Government Printer

Kenna, G.A and Lewis, D. C. (2008). Risk factors for alcohol and other drug use by health care workers. Substance abuse, Treatment, Prevention and Policy. vol. 3, 3. http://creativecommons.org/licences/by2.0. Accessed 2/3/2013.

NACADA (2002).Basic Informationon Drugand Substance Abuse Abuse.http://www.nacada.go.ke/ faqdetails.php? faq ID=9. Accessed 1/6/2012.

NACADA (2005). A Handbook on Prevention of Drug and Substance Abuse in Kenya. Nairobi: Ministry of Health.

NACADA (2006). Drug and Alcohol Studies. African Journal Vol. 5. No.1.[NACADA (2010). The role of parents in prevention and control of alcohol and drug abuse among their children in Nairobi. NACADA.

Ngesu, L.M., Ndiku, J. \& Masese, A. (2008). Drug dependence and abuse in Kenyan Secondary Schools: Strategies for intervention Educational Research and Review Vol. 3 No.10: 304-308. http://www.academicjournals.org/ERR. Accessed 2/2/2011.

Simiyu, R. N. (2011). Influence of illicit brew consumption on socio-economic status of households in Bungoma East District Kenya. MSc Thesis. Centre for Disaster Management and Humanitarian Assistance of Masinde Muliro University of Science and Technology. Amazon Books. Saarbrucken, Germany. Lap-Lambert Academic Publishing House. ISBN 978-3-8465-3053-5.

UNDCP (2006). Drug abuse. http:www.undcp.org/report_2006-01_1.html. Accessed on10/2/2011

Vlahov, D. (2002). Increased use of cigarettes, alcohol, and marijuana among Manhattan, New York, residents after the September 11 terrorist attacks. American Journal of Epidemiology Vol.155 No.11: 988-996.

WHO (2007). Global Status Report on Alcohol. WHO: Geneva.

WHO (2006). A Technical Paper on Public Health Problems of Alcohol Consumption in the Region. East Mediterranean. 